\title{
Epidemiological survey of urinary and intestinal schistosomiasis in Mayo-Louti Division, Northern Region Cameroon
}

\author{
1Saotoing P., 'Wadoube Z., ${ }^{2}$ Njan Nlôga A M. \\ 1: The University of Maroua, Higher Teachers' Training College, Department of Life and Earth Sciences \\ 2: The University of Ngaoundéré, Faculty of Science, Department of Biological Sciences \\ Corresponding author: psaotoing@yahoo.fr/psaotoing@gmail.com
}

Original submitted in on 30th July 2014. Published online at www.m.elewa.org on 30th September 2014. http://dx.doi.org/10.4314/jab.v81i1.9

\begin{abstract}
Objective: In order to determine the presence of bilharzia parasites in the populations, an epidemiological study on urinary and intestinal schistosomiasis was conducted from 09 September 2012 to 14 June 2013 in three villages namely: Badadji, Ouro-Marey and Kakala in Mayo-Louti Sub-Division, North Region Cameroon.

Methodology and results: A sample of 1080 people provided answers for the questionnaire and underwent urine and stools tests. The results revealed the presence of two types of schistosomes: Schistosoma haematobium and Schistosoma mansoni. The overall prevalence for these two species is $38.52 \%$. The prevalence of each species was higher for S. haematobium (28.85\%), S. mansoni (11.66 \%). The infestation did not depend on sex; prevalence is $20.92 \%$ for females against $17.60 \%$ for males. A non-significant difference was noted between the sexes $(X 2=2.534, \mathrm{df}=1, \mathrm{p}>0.05)$. Two types of infections affected all age groups with a clear dominance of Schistosoma haematobium in all age groups. Youth between 0-10 years were most affected by both species, with an average rate of $22.22 \%$ compared to $10-20$ years old (19.44\%) and $16.11 \%$ for adult who are more than 20 years old. The village of Ouro-Marey, with $47.22 \%$ of prevalence rate for Schistosoma haematobium is the most affected by the species against $27.77 \%$ and $5.55 \%$ for Kakala and for Badadji villages respectively. For cons, the Badadji village has the highest prevalence of S. mansoni $(32.77 \%)$ against $(1.11 \%)$ for each of the other two villages. The presence of ectopic egg in urine of $S$. mansoni $(0.18 \%)$ in a girl at Ouro-Marey shows that this village was a former home for the $S$. haematobium.

Conclusion: We have noticed that populations are unaware of existence of bilharzia parasite in their environment. They do not know the means or way of transmission the bilharzia. Infected people are needed to be treated and it is appropriate to sensitize the populations in order to avoid the contact with bilharzia.

Key words: Epidemiological survey, prevalence, schistosomiasis, stool, urine, North Cameroon.
\end{abstract}

\section{INTRODUCTION}

Bilharzia is a parasitic disease caused by flatworms of the genus Schistosoma. Adult worms infect the venous system and their eggs trigger human urinary problems, bowel, liver and spleen problems (WHO, 2011). Infection occurs when skin contact with infested waters schistosoma by bathing, washing peaches in hot endemic areas for schistosomiasis. The contamination is due in part to the absence of fecal and urinary health, contacts water snail men (fishermen, rice farmers, women and children) and secondary, the creation of water points: dam construction, irrigation development permanently 


\section{Saotoing et al. J. Appl. Biosci. 2014. Epidemiological survey of urinary and intestinal schistosomiasis in}

Mayo-Louti Division, Northern Region Cameroon

(Saotoing et al., 2011). Linked to poverty, it affects the socio-economic development of the populations (WHO, 2012). The morbidity is very important, but underestimated because it is clinically long and asymptomatic (Aubry, 2010). Schistosomiasis is opportunistic in certain infections such as HIV (Aubry, 2010). This is a serious public health problem in Cameroon (Tchuem Tchuente, 2005). In the world, schistosomiasis is the second human malaria parasite according to WHO (2013). It is estimated that 600 to 779 million people run high risk of schistosomiasis and about 200000 to 300000 are infected (WHO, 2012). The number of people needing treatment in the year 2011 was estimated at 243192887 (WHO, 2013) and there were 800,000 deaths per year (Aubry, 2010).There are three hundred thousand deaths per year in the subSaharan Africa (WHO, 2013). About 20 million Nigerians need a treatment against schistosomiasis, which makes it the most infested country in Africa and in the world (Carter Centre, 2013, WHO, 2013). In Cameroon, 5 million people (33\%) run the risk of schistosomiasis infection (PNLSHI, 2005), 2,000,000 $(13 \%)$ are currently infected and more than 10000 of new cases are detected per year (PNLSHI, 2005). The highest prevalence rate in $S$. mansoni infection and $S$. haematobium are identified in the three Northern regions of Cameroon (Brooker et al., 2000). In the Northern region, hydro facilities as Lagdo dam have increased the prevalence rate exponentially (Cunin et al., 2000). In addition, this disease has been confirmed in many villages of the Mayo- Louti Division (Deschiens et al., 1986; Cunin et al., 2000). Ranked among the Neglected Tropical Diseases

\section{MATERIAL AND METHODS}

Presentation of the study area: The study was conducted in three villages of the Mayo-Louti Division in the Northern Region of Cameroon. The first village is Badadji, located between $09.60^{\circ} \mathrm{North}$ latitude and $14.00^{\circ}$ east. It rises to $302 \mathrm{~m}$ above sea level. It is about $12 \mathrm{~km}$ from Figuil Sub Division headquarter of the locality. A river (Mayo Badadji) crosses the village and a swamp both considered as a temporary regime are the main places of water-relation- in this village. It is a cosmopolitan village with an estimated 4779 (Census ENP Enlarged Vaccination Programme, 2011) population. Those people come from the Far North Region (Mokolo,
(NTDs), several control methods are established: chemoprevention by Mass Distribution of Drugs (MDD)) based on the endemicity areas, the chemical and biological struggles, the public education (WHO, 2013). Today hope is based on the Bilhvax vaccine (Nau, 2009). In Cameroon, several methods of fighting against schistosomiasis are established; the creation of the" Centre Schisto " in 1999, the inclusion of this disease in the health sector strategy and the establishment of PNLSHI in 2003 ( PNLSHI, 2005). Despite all these efforts, schistosomiasis has increased and the number of infected people has increased prominently, $237,216,451$ in 2010 to 243,192,887 in 2011 (Aubry, 2010, WHO, 2013). The intensity of infection varies from one geographic area to another and depending on the parasite host (human, mollusc) and their environment (Belyhun et al., 2010). Thus, two neighbouring villages can have very different average rates of infection. This home distribution requires assessment of the level of endemicity in each locality (Rabarijaona, 1998). To plan, manage and effectively mobilize resources to fight effectively against human parasitic diseases, it is essential to carry out the estimation of the number and class of persons at risk of the contamination and better treatment in the world, by country and by region (WHO, 2011). This article proposes to determine the level of endemicity of schistosomiasis in the study area and specifically, to:

- determine the presence of bilharzia parasites in the populations of the explored areas,

- assess the prevalence of schistosomiasis among different age groups and sex.

- provide the remediation

Yagoua, Kaélé), the neighbouring Chad and other villages in the northern region. The second Village, OuroMarey is located between $09.68^{\circ}$ North latitude and $13.96^{\circ}$ East, Ouro-Marey has an altitude of $295 \mathrm{~m}$. It is about $18 \mathrm{~km}$ from the main town of Figuil Sud Division. The locality is watered by the Mayo- Louti and sometimes flooded by Mayo Kébi River. The third village is Kakala situated at $22 \mathrm{~km}$ from Figuil and about $50 \mathrm{~km}$ from Guider, its chief town. It is $257 \mathrm{~m}$ above the sea level and located between $09.66^{\circ}$ North latitude and $13.93^{\circ}$ East. It is surrounded by rivers in the West Mayo-Louti, the East and North by the tributary of the Mayo Kébi, in the South 
by the Mayo Kébi and Kakou Lake). The three villages are located on the map of Figure 1 in the appendix. The population of Ouro-Marey and Kakala village are mostly composed of Mambayes people. About 1444 and 1525 people live there (ENP Census, 2011). To this majority and indigenous ethnic groups, are added seasonal residents (seasonal workers) but who have settled there as time goes by. These are Guizigas, Toupouris, Massas,
Fallis, Guidars, Moundangs and Fulani herders who live peacefully with the natives. Broadly speaking, fishing, irrigated agriculture, laundry, dishwashing and daily bathing put these people in contact with fresh water. In fact, the majority of the inhabitants of these villages use more river water for domestic work than water from the wells and boreholes.

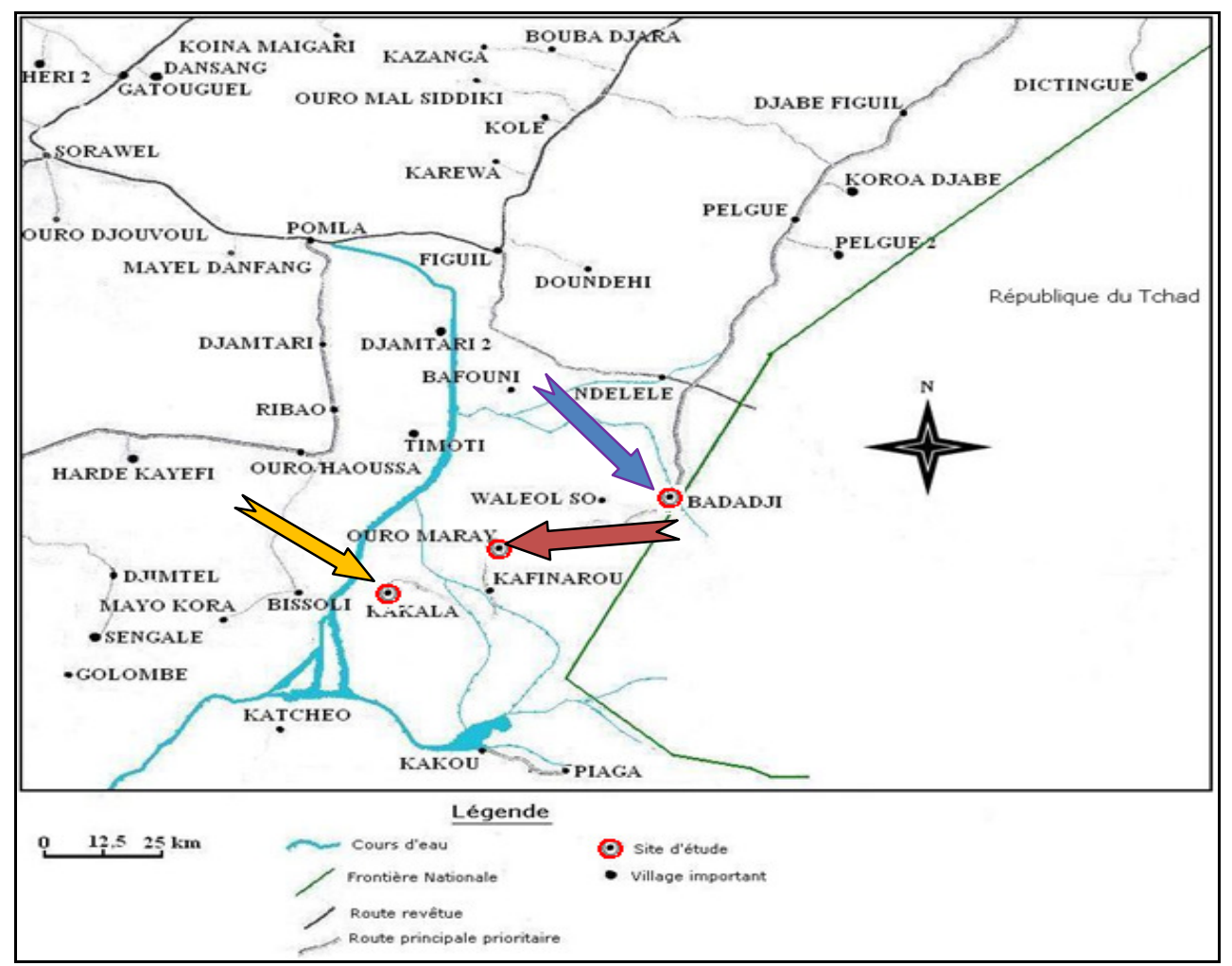

Figure 1: Study sites cards, SODECOTON sector, Guider, modified on the 12/06/2013

\section{Methodology}

Sampling: The target population consists of residents of the three villages mentioned above. In total 1080 people were actually interviewed and provided stool (1080) and urine (1080); or 360 people per village. This sample was equitably shared by sex (180 males and 180 females) and three age groups were people from 0 to 10 years (60), those 11 to 20 years (60), 20 years and over (60). The criteria for the inclusion of people in the study were to be an inhabitant in one of the three villages at least for one year (enough to have an experience on the epidemiological conditions of the medium term). By against the exclusion a criterion was a person not living in one of the three villages the duration of the residence in one of the villages less than one year. The target population met the criteria for inclusion in the study and was randomly selected.

Investigations: Survey type knowledge, attitudes and practices (KAP) of the target population was conducted in order to highlight the ways and customs of the people with respect to the knowledge of the disease, its treatment as well as prevention (Philippe et al., 2008). A prospective study based on the analysis of the urine and the stools of the population examined was conducted to the Centre Pasteur Annex Garoua (Camroon). After programming a schedule adopted by agreement with the village chiefs and heads of villages Health Centre concerned, was used to go to the chiefdom (Lawanat) or the Health Center once a week for the samples especially in the morning. Each person was given a stool pot sand a 
urine pot previously labelled while explaining the method of collection.

Sample Analysis: Once the samples were collected, they were taken to the laboratory of the Centre Pasteur Annex of Garoua for analysis. However, when the conditions were not met for immediate analysis, the samples were kept cool in a refrigerator at $4^{\circ}$. Once at Pasteur Centre, the samples were subjected to two tests: - Macroscopic examination in which the samples are described with the naked eye (Golvan et al., 1984.).

- Microscopic examination for the detection of schistosome eggs. Binocular microscopes of brand Leitz and various laboratory equipments were used. Each sample (urine and stools) was examined by three microscopic observations (Golvan et al., 1984). For the stool, the technique used was that of a direct observation of fresh water in physiological $\mathrm{NaCl} 9 \%$, which enabled the identification of eggs of Schistosoma mansoni. It was done as follows:

- A drop of saline $\mathrm{NaCl} 9 \%$ is deposited using a micropipette on slide object;

\section{RESULTS AND DISCUSSION}

The survey of the type KAP (knowledge, Attitudes and Practices) showed that $57.96 \%(626 / 1080)$ of people in the study area interviewed said they know about the disease and the name commonly used to designate it in foulfouldé is "nyaw cille naange" (Table 1). The males have a high knowledge of the urinary schistosomiasis. A significant difference $(X 2=21.32, d f=1, p<0.05)$ was found between males and those of females on the knowledge of schistosomiasis. This is due to the behaviour of Northern region inhabitants. In fact, in these regions, girls are expected to remain in homes (Saares) while the boys attend school and men spend more time
- A stools fraction is withdrawn with a micro - spatula and diluted with physiological water deposited on the blade; - The preparation is covered with a cover-slip in order to obtain a transparent thin to enable the search of $S$. mansoni eggs layer.

- The preparation is observed under an optical microscope, the first X10 objective perception of the image and then the X40 objective to make sharper and clearer image;

- The results are noted on the record corresponding to the stool samples examined.

Urines were centrifuged at 3000 revolutions per second using a centrifuge. The supernatant is poured and the withdrawals are carried out from the urinary sediments using a dropper. One to two drops of the urine sediment was deposited on a slide and covered with a cover slip. The total of urines collected was observed using an optical microscope (Leitz Microscope Binocular mark) to the X10 objective and after the image perception, the X40 lens for clear observation of this image. For each urine, the same procedure was repeated three times to increase the chance to meet with $S$. haematobium eggs.

outside the house in contact with other people. This allows men to be better informed than women. As for the earlier decision or not an anti-bilharzian on the 1080 people interviewed, $736(68.14 \%)$ reported that they had never received an anti-bilharzian treatment against only $31.86 \%$. The administration or not of praziquantel does not depend on gender $(X 2=1.2, d f=1, p>0.05)$. Women $(51.63 \%)$ are slightly more likely not to have yet taken praziquantel compared to men (48.37\%). The populations of the three villages surveyed have very few notions about the prevention of schistosomiasis.

Table 1: The answers of the patients on the knowledge of the bilharzia parasites and the taking in charge with a previous anti bilharzian drug.

\begin{tabular}{|l|c|c|c|c|c|}
\hline Villages & $\begin{array}{c}\text { Number of the } \\
\text { people interviewed }\end{array}$ & \multicolumn{4}{|l|}{ Answers to the questionnaire by the populations } \\
\cline { 3 - 6 } & & $\begin{array}{l}\text { Do you know something about } \\
\text { schistosomiasis? }\end{array}$ & $\begin{array}{l}\text { Did you take antibilharzian } \\
\text { treatment? }\end{array}$ \\
\cline { 3 - 6 } & & Yes & No & Yes & No \\
\hline BADADJI & 360 & 232 & 180 & 48 & 312 \\
\hline OURO-MAREY & 360 & 214 & 146 & 60 & 124 \\
\hline KAKALA & 360 & $\mathbf{6 2 6}$ & $\mathbf{4 5 4}$ & $\mathbf{3 4 4}$ & $\mathbf{7 3 6}$ \\
\hline Total & $\mathbf{1 0 8 0}$ & &
\end{tabular}

Average of the symptoms presented by the examined subjects: Table 2 below shows in descending order of importance in the three villages averages of the following symptoms : abdominal pain $(74.81 \%)$, itching $(60.37 \%$ 
), cough (59.25\%) pain while urinating (56.85\%), joint pain $(54.07 \%)$, diarrhoea (48.33\%), blood in the stool $(42.03 \%)$ and blood in the urine $(39.07 \%)$. In all the three villages, the average of the most recurrent symptoms that have a statistically significant difference with the schistosome infection are itching, abdominal pain, cough, pain when urinating and pain in the joints . These symptoms show the presence of two species of schistosomiasis encountered in the study area. Our results are similar to those found in the Democratic Republic of Congo Kiyanika group for $S$. mansoni by Mayaka, (2001).

Table 2: Prevalence rates of the bilharzia symptoms shown by the patients in three villages

\begin{tabular}{|l|c|c|c|c|}
\hline Symptoms & Frequencies & $\mathbf{X}^{\mathbf{2}}$ & $\mathbf{d f}$ & Prevalence rates \\
\hline Abdominal pain & $808 / 1080$ & 113,888 & 1 & $74,81 \%$ \\
\hline Itching & $652 / 1080$ & 17,597 & 1 & $60,37 \%$ \\
\hline Cough & $640 / 1080$ & 232,590 & 1 & $59,25 \%$ \\
\hline Pain while urinating & $614 / 1080$ & 9,072 & 1 & $56,85 \%$ \\
\hline Joint pain & $584 / 1080$ & 6,532 & 1 & $54,07 \%$ \\
\hline Diarrhoea & $522 / 1080$ & 2,600 & 1 & $48,33 \%$ \\
\hline Blood in the stool & $454 / 1080$ & 0,332 & 1 & $42,03 \%$ \\
\hline Blood on the urine & $422 / 1080$ & 0,008 & 1 & $39,07 \%$ \\
\hline
\end{tabular}

Prevalence of infection with schistosomes

By species: Previous studies have shown the prevalence of Schistosoma haematobium and Schistosoma mansoni in the Northern regions (Deschiens et al., 1986; Ratard et al., 1987; Same Ekobo, 1997 and Massenet et al., 2009). Through our investigations, it was found that Schistosoma haematobium and Schistosoma mansoni show prevalence rates of $26.85 \%$ and $11.66 \%$ respectively. The difference between the infestation S. haematobium and $S$. Mansoni is statistically significant $(X 2=40.02, \mathrm{df}=1, \mathrm{p}<$ $0.05)$. The high infestation rate of $S$.haematobium in this area compared to $S$. Mansoni is due to more favourable environmental conditions for the development of the intermediate hosts of these species at the expense of $S$. mansoni. In fact, Saotoing et al., (2011), justified the high infestation rate of $S$. haematobium among populations, which is due to the easy spread of parasite eggs in relation to $S$. mansoni eggs in the stool and which should first undergo its dilution before being scattered. The prevalence of S.haematobium and S. mansoniare shown in Figure 2 below. The overall prevalence of schistosomiasis is $38.52 \%$, which ranks the study site in meso- endemic area. This result confirms those found by
Deschiens et al., (1986) who credited the boroughs Guider and Figuil 20 to $49 \%$ for both species. It is intermediate between the hyper-endemic areas Bidzar Massenet et al., (2009) and Bibemi Deschiens et al., (1986), and Mayo- Oulo (77.4 \%) Same Ekobo, 1997), and those of low endemicity such as Benoue and Vina $(16 \%)$ for Schistosoma mansoni (PNLSHI, 2005). It was found that despite the equal distribution of praziquantel, this area has remained meso-endemic. This situation can be explained by the lack of basic hygiene and attendance of infested waters cercariae by people. One can also think of the contamination of the populations by the migration from hyper-endemic areas. In fact, to avoid recurrent famines in certain parts of the North Cameroon, famines is due to chronic deficit rainfall, the populations migrate to the managed areas such as the hydro (dams) or areas with natural water retention (natural lake or permanent stream). However, these areas are of high risk in terms of health (Urbani et al., 1997; Mouchet and Carnevale, 1997). Populations who migrate are likely to come from areas with a high prevalence of parasitic infestation, which significantly increases the risk of the spread of parasites in these areas. 


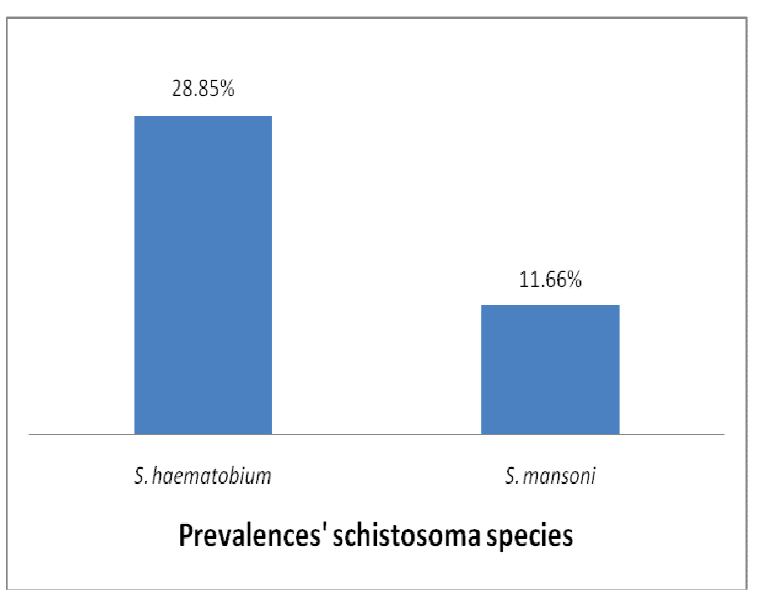

Figure 2: Parasite prevalence rates by the schistosomasis specie

By sex: The analysis of Figure 3 below shows that both sexes are affected by schistosomes with a predominance of females $(20.92 \%)$ against (17.59 \%) for males. The gender difference was not statistically significant $\left(X^{2}=\right.$ $2.534, d f=1, p>0.05)$. Our results corroborate those of Same Ekobo, (1997) who also found that the rate of $S$. haematobium in children is high and predominantly in girls in Kekem Sub division. These results are contrary to those found in the foyer of the Benoue: $42.2 \%$ men against $37.7 \%$ of infected women with a statistically significant difference. Elias Ndamkou in 1994 and 1986 cited by Same Ekobo, (1997) also showed that in general, the prevalence rate is higher in men than in women due to permanent contact with" water man" especially with males. In our research area, this contact seems rather greater in females.

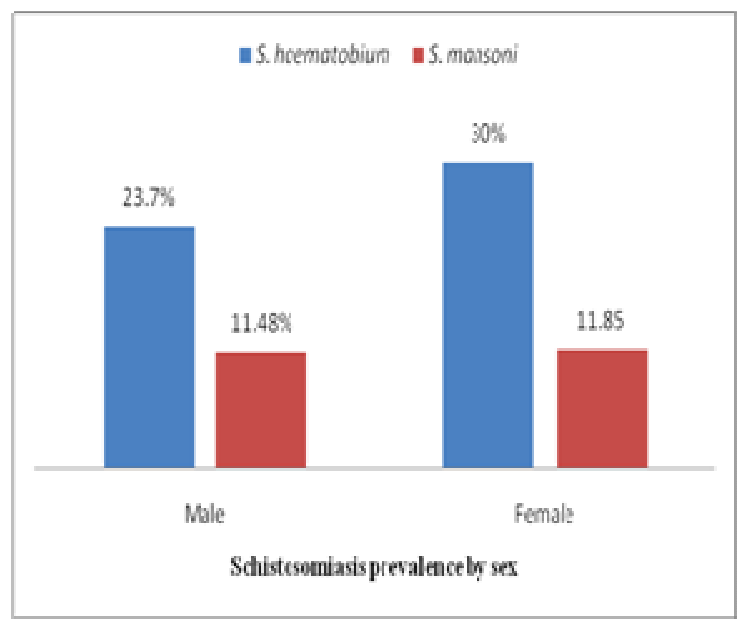

Figure 3: Prevalence rates of infestation by species and gender

In fact, in addition to the laundry, dishes, bathing and agricultural work, women engaged in fishing creels while men use nets and fishing in canoes, therefore confirming the different results of the work, it is difficult to conclude on the receptivity of schistosomes by gender. In general, cases of contamination would be more related to environmental factors, the level of endemicity and especially the activities performed (Saotoing et al., 2011). By age : Figure 4 below shows that all age groups are affected by schistosomiasis. There was no statistically significant difference between group ages $(X 2=5.693 \mathrm{df}$ $=2, p>0.05$ ). However, the most affected age group is $[0-10$ years $[(44.44 \%)$ and the less affected age group is [20 years and $+(32.22 \%)$. The high rate of infection in the age group [0-10 years] can be explained through laundry and dishes (girls). It should be noted that the prevalence is decreasing with age. This decrease is due to the existence of immunity among older, the retention of high tissue eggs or adults, which are relatively low - water contact (Same Ekobo 1997; Aubry, 2008). Our results 


\section{Saotoing et al. J. Appl. Biosci. 2014. Epidemiological survey of urinary and intestinal schistosomiasis in}

Mayo-Louti Division, Northern Region Cameroon

corroborate those of Saotoing et al., (2011); Boisier et al., years. Some authors justify this by the lack of compliance (2001) who have found a high prevalence in people of 10 with hygiene rules.

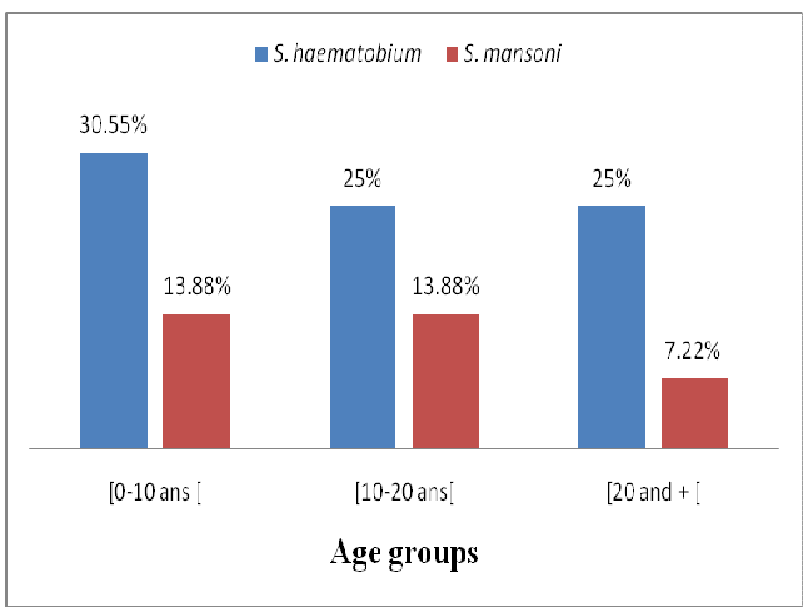

Figure 4: Prevalence rate of the infestation by specie and age ranges

\section{CONCLUSION AND REMEDIATIONS}

The epidemiological survey carried out in the year 2013 in the three villages (Badadji, Ouro-Marey and Kakala) in the Mayo-Louti Division in the North Region Cameroon, revealed the presence of two types of frequent schistosomes: Schistosoma haematobium and Schistosoma mansoni. The global prevalence rate of these types is $38.51 \%$, considering the site as mesoendemic zone. The global prevalence rate by specie is higher for the S. haematobium $26.85 \%$ compared to the Schistosoma mansoni whose prevalence rate is $(11.66 \%)$. It should also be noticed that the two genders (male and female) are contaminated by the two schistosomiasis species with high prevalence of the $S$. haematobium in all the age ranges. Youths ranging from [ $0-10$ years are infected with a prevalence rate of $22.22 \%$ against youths ranging from [10-20 years old with a percentage rate of [ 19.44 and $16.11 \%$ for adults who are [20 or more years old [. Ouro-Marey, with a prevalence rate of $47.22 \%$ of the $S$. haematobium is the most affected village by this specie against $27.77 \%$ for Kakala and $5.55 \%$ Badadji villages respectively. Consequently,

\section{APPRECIATION}

We extend our profound gratitude to all the populations who in one way or the other have accepted to participate in this research work, namely the Centre Pasteur Annexe of Garoua for the equipment they put at our disposal and
Badadji village presents the highest prevalence rate according to Schistosoma mansoni, which is $32.77 \%$ against $1.11 \%$ for Kakala and Ouro-Marey villages respectively. The presence of an ectopic egg in a female patient according to $S$. Mansoni in Ouro-Marey village confirms the fact that it is an old zone of the prevalence of $S$. haematobium. To stop the spread of bilharzia parasites and reduce their morbidity rates, it would be advisable for sanitary and administrative authorities to:

- $\quad$ Treat the entire population of the affected areas, - $\quad$ Have a prolonged control on patients and renew the tests each time,

- $\quad$ Construct latrines in the various schools,

- Think of chemical and biological fight against the disease.

The continuation of the present work on the malacological study of lake Kakou, the water of rivers Mayo-Louti and Mayo-Kebi which are some eventual sites of infestation would throw more light on the different intermediary hosts which are in that area.

to all those who contributed to the success of this research work. We are grateful to the authorities of the University of Maroua from whom we received funding to publish this research work.. 


\section{REFERENCES}

Aubry P., 2008. Schistosomes ou bilharzioses, la revue du praticien, 57,149-155

Boisier P., Ramarokoto C. E., Ravoniarimbinina P., Rabarijaona L. andRavaoalimalala, V.E., 2001. Tropical Medecin and International Health, 6, 699- 706 .

Belyhun Y., Medhin G., Amberbir A., Erko B., Hanlon C., Alem A., Venn A., Britton J. and Davey G., 2010. Prevalence and risk factors for soil-transmitted helminth infection in mothers and their infants in Butajira, Ethiopia: a population based study, BMC Public Health, pp1471-2458.

Brooker S., Donnelly C.A and Guyatt H. M., 2000. Bulletin of the World Health Organisation, 78, 1456-1465.

Carter Center. 2013

Cunin P.,Griffet A.,Poste B., Djibrlla K. and Martin M. V., 2000. Epidemic Schistosoma mansoni in an known S. haematobium area. Transaction of the royal society of tropical medicine and hygiene, $94,657-660$.

DeschiensR., Delas A., Ngalle-Edimo S. et Poirier A. 1986. Projet de recherche sur la bilharziose: enquête scolaire, Province du Nord Cameroun.

Golvan Y. J., et P. ambroise T., 1984. Les nouvelles techniques en parasitologieFlammarion Médecine-Sciences 32p.

Massenet D., Inrombe J., Dawaye O., Abdoulaye Y., Portal J. L., Boisier P. etTchuem Tchuente L. A., 2009. Schistosomiasis in the North Region of Cameroon: unexplained decrease in prevalence among schoolchildren between 1986 and 2008 , 2009. Annals of Tropical Medecine \& Parasitology, vol. 103, N ${ }^{\circ}$ 8, pp 745-750 (6).

Mayaka, M. S., 2001. Étude épidémiologique de la bilharziose à Schistosoma mansoni en milieu scolaire: cas du groupement de Kiyanika. Mémoire de Doctorat. Universités de Kongo. Faculté de médecine. 58p.

Mouchet J. et Carnavale P., 1997. Impact des transformations de l'environnement sur les maladies à transmission vectorielle. Cahier santé, 7, 263-269.

Nau J. Y., 2009. «Bilhvax International Journal of tropical Medicine, 6 (2): 19-24. »: un premier vaccin contre la bilharziose. Rev Med Suisse; 5:2535

OMS, 2011. Tout ce que les enfants doivent savoir sur la schistosomiase. Bambo à la schistosomiase. Organisation Mondiale de la santé, 22p.People at risk. Lancet Infectious Diseases, 6:411-425.
OMS, 2012 Schistosomiase: population ayant besoin d'une chimio-prévention et nombre de personnes traitées en 2010. №. 4, 87, 37-44

OMS, 2013. Relevé épidémiologique hebdomadaire No. $2,88,17-28$

PNLSHIC.2005. Programme National de Lutte contre la Schistosomiase et les Helminthiases Intestinales au Cameroun: plan stratégique 2005-2010. 92p.

Rabarijaona L. P., 1998. Validation de l'emploi des méthodes LQAS pour l'identification des communautés cibles du Programme National de lutte contre la Bilharziose à Madagascar. [Mémoire de D.E.A d'Epidémiologie et intervention en santé publique]. Bordeaux: Institut de Santé Publique, d'Epidémiologie et Développement.

Ratard R. C., 1987. Le schistosome africain. USAID Document, 4,6.

Samé Ekobo A., 1997. Santé, Climat et environnement au Cameroun, Ed. Jutey-Sciences. 329 p.

Saotoing P., Vroumsia T., Njan A. M. Tchuenguem F.N. and Messi J., 2011. Epidemiological survey of schistosomiasis due to Schistosoma haematobium in some primary schools in the town of Maroua, Far North Region Cameroon. International Journal of Tropical Medicine; Volume: 6(2), 19-24.

Tchuem Tchuente L.A., 2005. Lutte contre la schistosomose: défi et perspectives pour le XXle siècle

Urbani C., Touré A., Hamed A. O., Albonico M., Kane I., Chekna D., Hamed N. O., Montresor A. et Savioli L., 1997. Parasitoses intestinales et schistosomiases dans la vallée du fleuve Sénégal en République Islamique de Mauritanie. Médecine Tropicale, 57, 157-160.

P. Guilbert; D. Haziza; A. Ruiz-Gazen et Tille Y., 2008. Méthodes de sondage: enquête électorales, enquêtes dans le domaine de la santé, enquêtes dans les pays en développement. 380p.

WHO, 2011. Soil-transmitted helminthiasis: estimates of the number of children needing preventive chemotherapy and number treated, 2009. Weekly epidemiological record, 25 (86), 257268

WHO, 2013. Weekly epidemiological record No. 8, 2013, $88,81-88$. 